\title{
Effects of Adult or Perinatal Hormonal Environment on Ultradian Rhythms in Locomotor Activity of Laboratory LEW/Ztm Rats
}

\author{
FRANZISKA WOLLNIK ${ }^{1}$ \\ Central Animal Laboratory at the Medical School Hannover, D-3000 Hannover 61, F.R.G. \\ AND \\ KLAUS-DIETER DÖHLER \\ Department of Endocrinology at the Medical School Hannover, D-3000 Hannover 61, F.R.G.
}

Received 13 June 1985

\begin{abstract}
WOLLNIK, F. AND K.-D. DÖHLER. Effects of adult or perinatal hormonal environment on ultradian rhythms in locomotor activity of laboratory LEW/Ztm rats. PHYSIOL BEHAV 38(2) 229-240, 1986.-Four experiments were performed with male and female rats of the inbred strain LEW/Ztm maintained under a light-dark schedule of 12:12 hours. The animals were subject to castration (GOX) or ovariectomy (OVX), estradiol 17 $\beta$-implantation (E2-capsules), and perinatal hormonal treatments with testosterone propionate (TP) and an androgen antagonist (cyproterone acetate, CA). Results indicated a difference in the locomotor activity pattern between the two sexes as a result of the endogenous estradiol levels of the adult animals. The activity pattern of male LEW rats was characterized by ultradian rhythms of 4 and $4.8 \mathrm{hr}$ periods. The female LEW rats, on the other hand, generally exhibited a clear circadian activity pattern and no ultradian activity rhythms. Following ovariectomy, each of the females showed distinct ultradian rhythms. These disappeared after E2-implantation. Castration of adult males had no effect on the ultradian activity pattern. Implantation of E2-capsules resulted in a marked decrease of the ultradian activity components. Perinatal treatment of the males with an androgen antagonist (CA) did not appear to effect ultradian rhythms during adulthood. Females treated perinatally with testosterone showed a significant increase in the ultradian activity components. This effect is assumed to be due to low estrogen levels in these animals during adulthood. Our study supports the assumption that ultradian rhythms are a result of changes in the phase relationships between several circadian oscillators. The synchrony of these oscillations seems to be facilitated by estradiol.
\end{abstract}

Ultradian rhythms Locomotor activity Gonadectomy Estradiol Testosterone Brain differentiation Laboratory rat

SEVERAL well-known phenomena of circadian rhythms in mammals can be explained by the model of the circadian system as a composite of multiple, highly ordered oscillators $[40-42,46]$ located in or close to the suprachiasmatic nuclei in the hypothalamus [47]. The origin of similar temporal variations on a smaller time scale, called ultradian or short-term rhythms, remains unclear [11]. Ultradian rhythms in locomotor activity are known to exist in laboratory rats $[8,9,28-30$, 49], however, attracting much less attention than circadian rhythms.

A recent study of $\mathrm{LEW} / \mathrm{Ztm}$ rats has shown that ultradian rhythms of 4 and $4.8 \mathrm{hr}$ periods are genetically fixed in this inbred strain [9]. The persistence of these ultradian rhythms following the disruption of circadian organization under continuous light supported the assumption that the activity rhythms of this strain are caused by an independent ultradian oscillator [9]. Alternatively, the persistence of ultradian rhythms can be explained by changes in the phase relationships between several circadian oscillators [46].

The ultradian rhythms of the inbred strain LEW/Ztm are sex-specific, being observed only in the males [56]. The question, therefore, arises as to whether the ultradian rhythms are the result of endocrine factors. Several studies have documented clear effects of gonadal hormones on the

${ }^{1}$ Requests for reprints should be addressed to Dr. Franziska Wollnik, Northwestern University, Department of Neurobiology and Physiology, Evanston, IL 60201. 

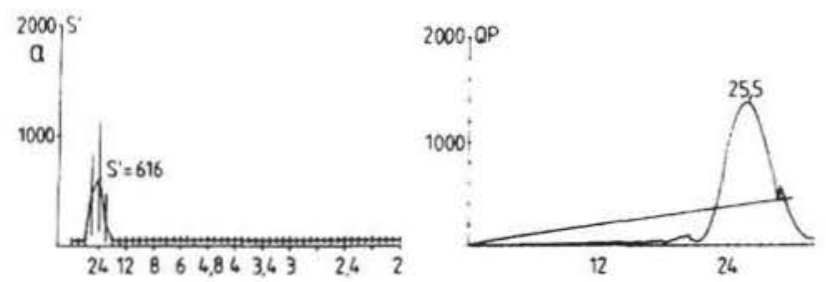

circadian system of mammals and birds [51]. Melatonin has been reported to shorten the freerunning period of activity and to induce continuous activity in the house sparrow [52]. Castration in mice resulted in a lengthening of the circadian running-wheel behavior, whereas continuous testosterone treatment reversed the effects of castration [12]. Testosterone, furthermore, modulated the duration of activity and induced "splitting" of the circadian locomotor activity pattern in the starling $[24,25]$.

"Splitting" is defined as rapidly occurring transient dissociation of two oscillations which temporarily free-run with different circadian frequencies. In female hamsters and rats, exogenous estrogen shortened the free-running period of activity in a light dark cycle $[1,36]$. The phase and level of activity, therefore, appeared to vary with the estrous cycle $[2,19]$. A recent report [34] using female hamsters also indicated that low estrogen levels induce "splitting." These various effects of gonadal steroids on the synchronization of the multi-oscillatory circadian system are of great interest lending an explanation to the observed sex-differences in the ultradian activity rhythms of the LEW strain.

Furthermore, it is also known that the brains of male and female rats differ functionally and also in the morphology of the suprachiasmatic nuclei $[22,33]$. These sex-related differences in brain function are established during an early critical stage of development, apparently by the masculinizing effect of androgens on the developing brain $[3,14,21]$. Preliminary reports with rats and hamsters indicate that perinatal exposure to androgens also permanently influences the organization of the circadian system [1. 13, 58].

The purpose of the present study was to examine the effects of perinatal and/or adult hormonal environment on the ultradian activity rhythm of the inbred rat strain $\mathrm{LEW} / \mathrm{Ztm}$. The experiments provide no evidence of perinatal hormonal treatment having an effect on the ultradian rhythms. It does seem certain, however, that the sexrelated difference is caused by the dissimilar hormonal environments of the adult animals. Further findings indicate estradiol as being important in suppressing the ultradian rhythms in females as well as in males, thereby identifying an additional function of estradiol on the activity rhythms of rats.

\section{GENERAL METHOD}

\section{Animals and Maintenance Conditions.}

The inbred rat strain LEW/Ztm has been found to exhibit genetically fixed $[8,9]$ as well as sex-specific [56] ultradian activity rhythms. In addition to the limitation of ultradian rhythms to the males, it is likewise peculiar that the brief reproductive period of the females ends between 4 and 5 months of age (Döhler, unpublished observations). The strain itself is the result of strong inbreeding systems such as continuous brother-sister matings over at least twenty generations [17]. Individuals of this strain, therefore, provide a convenient material of genetically identical animals.

Both sexes were bred and raised in our laboratory under a light-dark cycle of LD 12:12 and controlled environmental conditions (room temperature $22 \pm 1^{\circ} \mathrm{C}$, relative humidity $55 \pm 5 \%$ ). The animals were free of all pathogens specified in the GV-SOLAS list [23]. During the course of the measurements, the animals were individually kept in polycarbonate cages (Makrolon Type III, $55 \times 33 \times 20 \mathrm{~cm}$ ) on sterile wooden granules. A pelleted diet (Altromin 1324) and tap water from Makrolon bottles were available ad lib. The rooms were entered once a week for animal maintenance. The animals
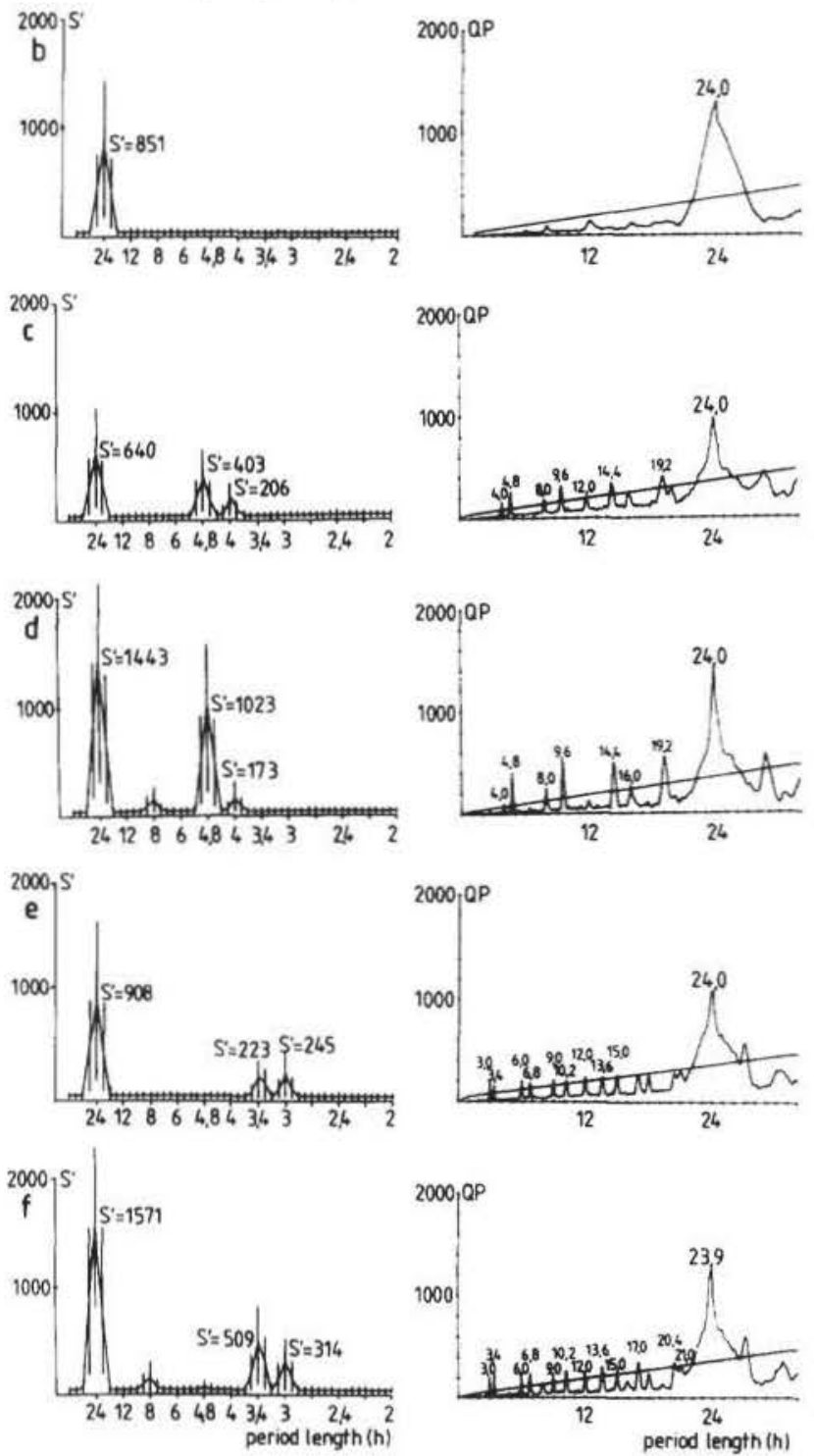

FIG. I. Analysis of artificial data by the spectral analysis $[26,38]$ and the chi square periodogram [48]. Input data consisting of 17285 -min values ( $=6$ days) of the following functions were generated by a computer: (a) Cosine function of $25.5 \mathrm{hr}$ period and an amplitude of 50 arbitrary units. A range of random numbers from +50 to -50 was added. (b) Saw tooth function of $24.0 \mathrm{hr}$ period with an increase of the amplitude from 0 to 100 arbitrary units. A range of random numbers from +100 to -100 was added. (c) Cosine functions of $\mathrm{P} 1=24.0 \mathrm{hr}, \mathrm{P} 2=4.8 \mathrm{hr}$, and $\mathrm{P} 3=4.0 \mathrm{hr}$ period with amplitudes of $A 1=50, A 2=40$, and $A 3=30$ arbitrary units. $A$ range of random numbers from +180 to -180 was added. (d) Square wave functions of $P 1=24.0 \mathrm{hr}, \mathrm{P} 2=4.8 \mathrm{hr}$, and $\mathrm{P} 3=4.0 \mathrm{hr}$ period with amplitudes of $A I=60, A 2=50$, and $A 3=20$ arbitrary units. A range of random numbers from +150 to -150 was added. (e) Cosine functions of $\mathrm{PI}=24.0 \mathrm{hr}, \mathrm{P} 2=3.4 \mathrm{hr}$, and $\mathrm{P} 3=3 \mathrm{hr}$ periods with amplitudes of $A 1=60, A 2=40$, and $A 3=30$ arbitrary units. A range of random numbers from +150 to -150 was added. (f) Square wave functions of $\mathrm{P} 1=24.0 \mathrm{hr}, \mathrm{P} 2=3.4 \mathrm{hr}$, and $\mathrm{P} 3=3 \mathrm{hr}$ periods with amplitudes of $A 1=60$ and $A 2=A 3=30$ arbitrary units. A range of random numbers of +150 to -150 was added. 

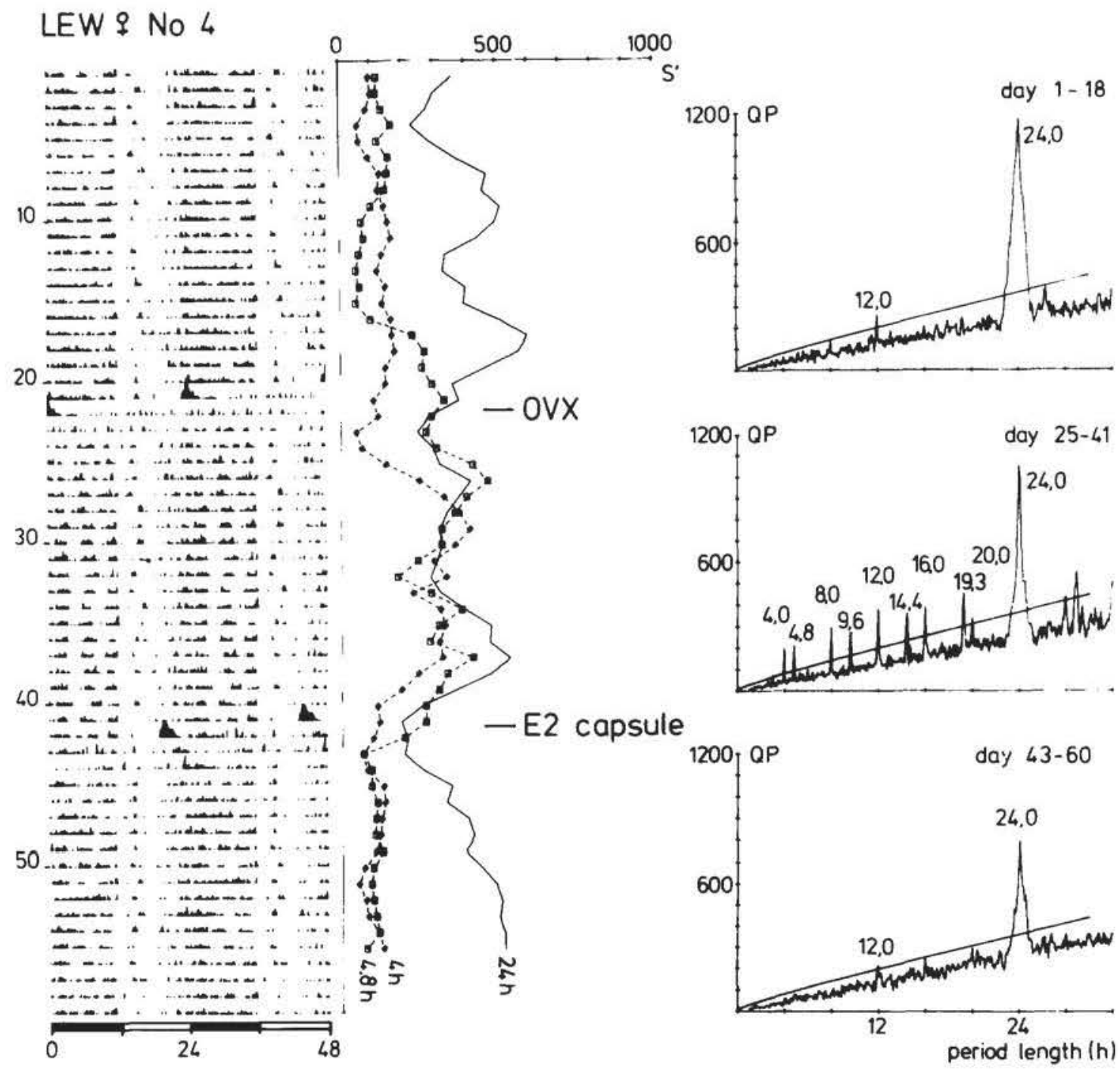

FIG. 2. Left: Double plotted locomotor activity record of a female LEW rat (No. 4) under LD 12:12. The animal was ovariectomized $(\mathrm{OVX})$ on day 21 . Estradiol-17 $\beta$ implantation (E2-capsule) occurred on day 42 . Surgery was performed during the light period of the lighting regime. A 3-4 hr interval of total rest is followed by a distinct peak of highly increased activity. Middle: Continuous spectral analysis: 6-day intervals were shifted over the total registration period in one day steps. For each of these 6-day intervals a spectral analysis similar to Fig. 3 was calculated according to Halberg and Panofsky [26,38]. The amplitudes of distinct spectral estimates, i.e., 24-hr (-), 4.8-hr ( $\square$ ), and 4-hr ( $)$ were appointed to the first day of the interval. Right: Chi square periodogram for distinct time intervals. The sloping line represents $p \leqslant 0.001$ $\left(\chi^{2}\right)$ as derived according to Sokolove and Bushell [48]. For interpretation of the ultradian peaks see the Apparatus and Data Analysis section.

were provided with new cages, food, and water every 3 weeks during long-term recordings.

\section{Apparatus and Data Analysis}

Locomotor activity was recorded with an electronic movement analyzer; which operating on a capacitant system [44] supplies a continuous signal proportional to the horizontal movement of the animal. The output was recorded at 10 -sec intervals by a microcomputer (Apple II).

Five-min mean values were calculated from the 10 -sec intervals. All further calculations were based on these 5-min averages. Due to the inconsistency in the body weights of the animals, the intensity of the output signals from the capacitant recording system varied. The measurements of locomotor activity were standardized by setting the overall mean value of each animal at $100 \%$. Event records were printed at 5-min intervals over 48-hr time scale with each day being repeated for continuity (double plot). Analysis of ultradian rhythms in the presence of a circadian rhythm is a difficult problem. We therefore used two different mathematical techniques to examine the periodicity of the locomotor activity data. The results of the two methods were compared in order to check the reliability of each method. Statements about the periodicity of each animal were based on the application of both methods.

The "generalized harmonic spectral analysis" devised originally by Tukey [5] rests upon the mathematical principle that any finite sequence of discrete data taken at regular intervals can be fully and completely characterized as dis- 
crete values taken at identical intervals from the sum of a finite series of sine and cosine waves, known as the Fourier components of the data.

We used a computational method described by Halberg and Panofsky $[26,38]$ for this type of analysis, whereby the point of departure for the calculations was an autocorrelation function of the original data. This method evaluates the statistical significance of circadian rhythms as well as oscillations having periods longer or shorter than circadian rhythms. The only limitation is given by the fact that the maximum meaningful resolution attainable is a spectral estimate for each of T values of frequency (where $T$ is the total length of the data series). These components will differ from each other in frequency by steps of $1 / \mathrm{T}$. Thus, spectral estimates were attainable for only distinct periods (i.e., $24 \mathrm{hr}$, $19.2 \mathrm{hr}, 16 \mathrm{hr}$, etc.). The amplitudes $\mathrm{S}^{\prime}$ of distinct spectral estimates are a measure of the extent to which oscillations of various period lengths contribute to the total variability of a time series. The statistical reliability given by the $95 \%$ confidence limits could be improved by pooling the spectral estimates of individuals; in this case animals of the same experimental protocol. Differences between the amplitude of the spectral estimates of a distinct period were tested statistically by $t$-tests.

In addition, we used the chi square periodogram to determine the exact period length of ultradian rhythms. This method is not bound by any implicit assumption about the wave form of the dominant rhythmic components. The calculation procedure developed by Sokolove and Bushell [48] suggests a slightly different statistic than that originally recommended by Enright [16]. Here a simple test determining the significance of a periodogram peak was proposed and the sensitivity of the method was examined for detecting periodicity in the presence of random fluctuations and for resolving periodic components of similar amplitude, but with slightly different periods. The periodogram has already been calibrated with a variety of artificial as well as biological data. A broad description of several deficiencies of the procedure, particularly when certain kinds of non-stationarity are present, was given by Enright [16]. Other calibrations of the periodogram, using several different types of biological rhythm data, have been undertaken $[7,45]$ as well as comparisons of the periodogram with the autocorrelation function and the power spectrum [6].

Because both methods, the spectral analysis and the periodogram, were originally designed for the detection of only circadian rhythms, we tested the usefulness of these methods for the detection of ultradian rhythms with simulated data. The input data were generated by computer and contained random fluctuations as well as circadian and ultradian rhythms of different period, amplitude and wave form. Representative analyses are given in Fig. 1.

Although the number of data was limited ( 6 days), both methods proved convenient for the analysis of our data. Amplitudes of the spectral estimates and the periodogram peaks were correlated to the "true" amplitude of the artificial input data, although the wave form and the level of the "random noise" also affected the amplitude. Two rhythms of different amplitude having the same wave form and amplitude resulted in spectral estimates of nearly the same amplitude. One complication in the periodogram is evident when analyzing circadian rhythms. The analysis cannot tell whether the identified components are actually present, or whether the periodogram peaks arise due to a component the period of which is a submultiple $(1 / 2,1 / 3$, etc. $)$ of the apparent
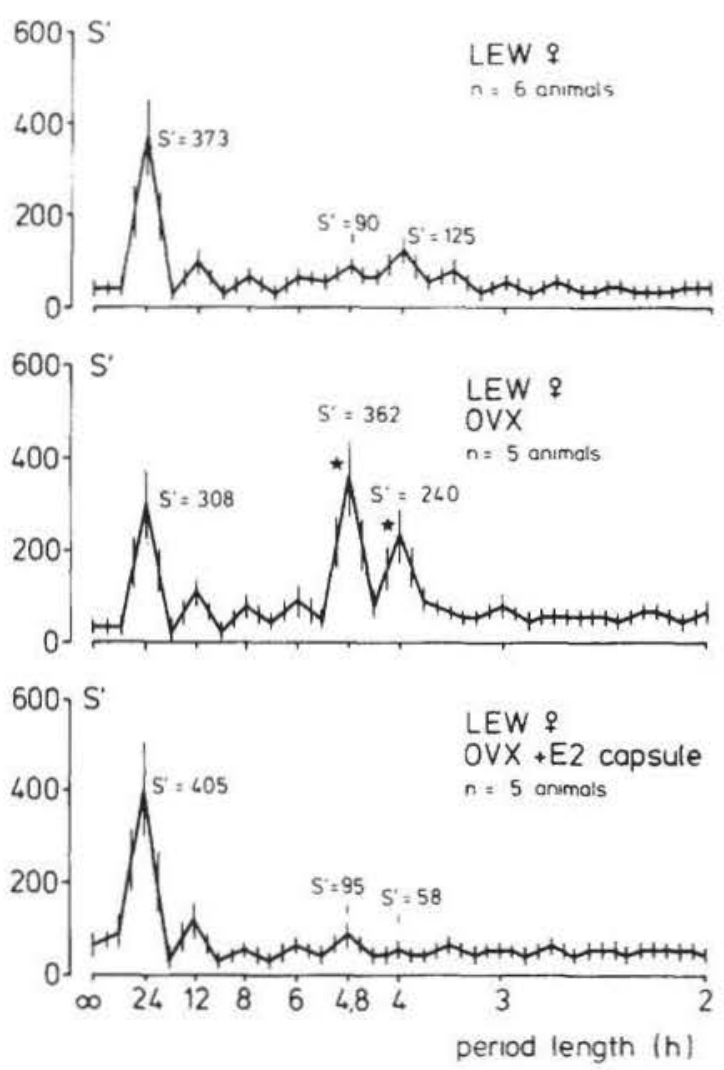

FIG. 3. Spectral analysis of the LEW females pooled for the time before ovariectomy (days 1-18), after ovariectomy (OVX, days 25$41)$, and after estradiol implantation (OVX + E2-capsules, days 4360 ). The $95 \%$ confidence limits of the spectral estimates are plotted as vertical lines. The 4 -hr and 4.8 -hr spectral estimates of the ovariectomized animals are marked with stars. These values differ significantly $(p \leqslant 0.01)$ from the corresponding values before and after ovariectomy.

values. An ultradian rhythm of $4.8 \mathrm{hr}$ period will produce periodogram peaks at $9.6 \mathrm{hr}$ as well as at $14.4 \mathrm{hr}$ and $19.2 \mathrm{hr}$. Closer examination of the periodogram resolves this ambiguity. If the periodogram contains a repeating pattern, the "true" period length can be assigned to the appropriate submultiple of the periods at which the repeating peaks occur.

Significant ultradian rhythms were not caused by non-stationarities or asymmetry of a 24-hr rhythm in any of the analyzed examples.

EXPERIMENT 1: EFFECT OF OVARIECTOMY AND ESTRADIOL. REPLACEMENT ON THE ACTIVITY PATTERN OF ADULT LEW/Ztm FEMALES

\section{Method}

Locomotor activity was measured under LD 12:12 in 6 adult female rats of the LEW/Ztm strain starting at approximately 80 days of age. As a control, locomotor activity of these animals was recorded under these conditions for 20 days. On day 21 , the animals were ovariectomized (OVX) under anesthesia (100 mg/1 kg b.wt. Ketavet, Parke, Davis \& Company, München, $+0.05 \mathrm{ml}$ Rompung Bayer Leverkusen, IP) and were monitored for an additional 20 days. The surgery took place in the experimental room during the light period of the lighting regime. 

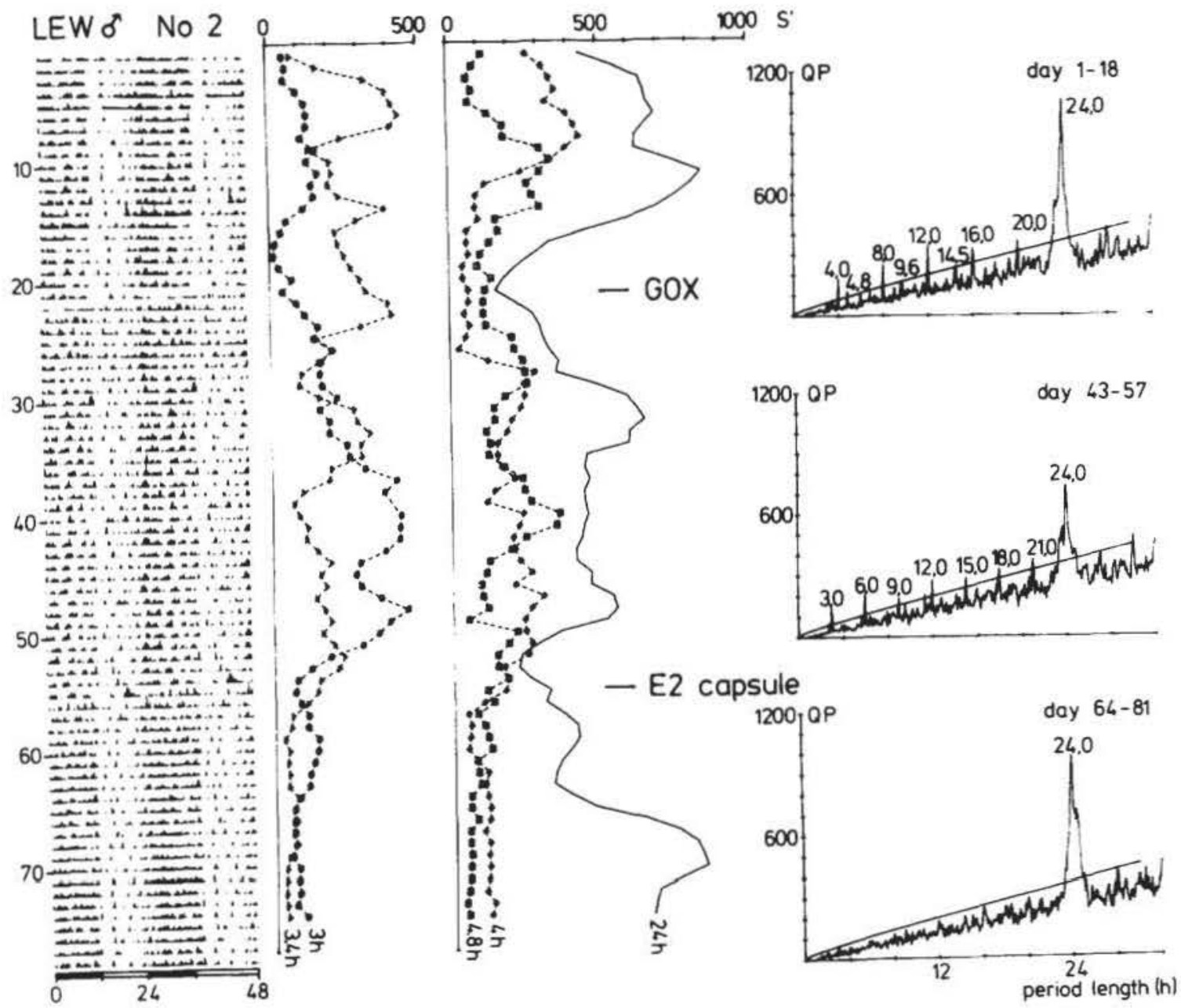

FIG. 4. Left: Double plotted activity record of a male LEW rat (No. 2) maintained under LD 12:12. The animal was castrated on day 21 (GOX). Estradiol-17 (E2-capsule) was implanted on day 56. Middle: Continuous spectral analysis with estimates for the 24-hr (-), the 4.8-hr $(\square)$, the 4-hr $(\diamond)$, the 3.4-hr $(\Delta)$, and the 3-hr $(O)$ components. For details see Fig. 1. Right: Chi square periodogram of distinct time intervals. The sloping line represents $p \leqslant 0.001\left(\chi^{2}\right)$ as derived according to Sokolove and Bushell [48]. For interpretation of the ultradian peaks see the Apparatus and Data Analysis section.

On day 42 , the animals were implanted with Silastic capsules (Dow-Corning, $1.57 \mathrm{~mm}$ i.d., $3.18 \mathrm{~mm}$ o.d.) filled to 15 $\mathrm{mm}$ with estradiol-17 $\beta$ (E2-capsule). Estradiol capsules of this size are reported to produce a relatively constant proestrus-like level of estradiol in ovariectomized SpragueDawley rats [32]. The capsules were incubated in water $\left(21^{\circ} \mathrm{C}\right)$ for 30 min prior to implantation in order to minimize initial transitory hormone release. The E2-capsules were implanted subcutaneously in the lower dorsal thoracic region of the anesthetized rats.

The measurements of locomotor activity were continued for a total of 60 days. A processing failure caused the loss of data from one rat after day 22 . Once activity recordings ceased, the animals were sacrificed with an overdose of anesthetic and were examined for the presence of the Silastic implant. The $15-\mathrm{mm}$ estradiol Silastic capsules released $14.81 \pm 2.27 \mu \mathrm{g}$ estradiol/day (means $\pm \mathrm{SD}$ ). These values were determined by the difference in dry weight of the capsules before and after implantation. Vaginal smears were not taken during the experiment. Inherent handling would have disrupted the activity pattern.

\section{Results}

Figure 2 demonstrates the effects of ovariectomy and estradiol replacement on a representative female rat of the $\mathrm{LEW} / \mathrm{Ztm}$ strain. The activity record is shown on the left side. A continuous spectral analysis appears in the middle of the figure. During the first 20 days under the LD 12:12 control period, the activity of the representative animal in Fig. 2 exhibited a clear 24-hr rhythm. The amplitude of the 24-hr spectral estimate ranged from $S^{\prime}=300$ to $S^{\prime}=500$ for the entire registration period. The amplitudes of the $4-\mathrm{hr}$ and 4.8-hr spectral estimates were very low during the first 20 days. Shortly after ovariectomy (OVX), the activity pattern changed. At first, very short activity bouts were observed during the whole day. Within a few days post surgery, a stable pattern with 3-4 activity peaks occurred during the night phase, resulting in a marked increase of the amplitudes of the 4-hr and 4.8-hr spectral estimates. Implantation of an estradiol capsule on day 42 (E2-capsule) abolished the effect of ovariectomy. The activity record indicated no regular activity peaks during the night. The amplitudes of the $4-\mathrm{hr}$ and 
LEW ơ No 1-CA
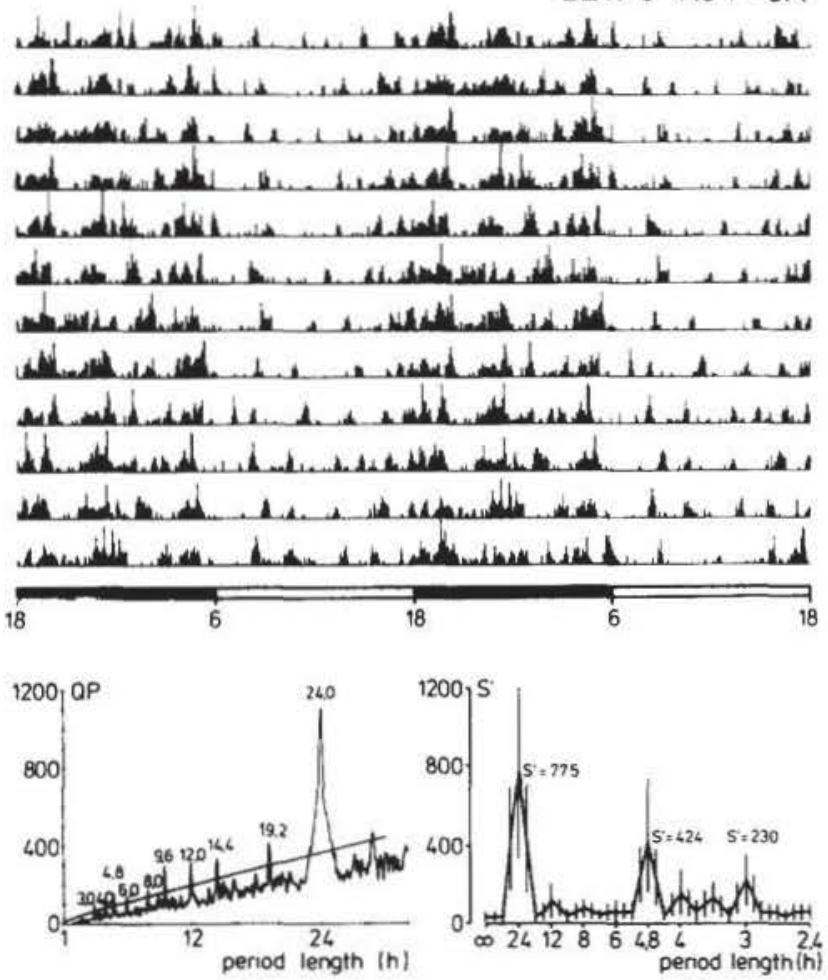
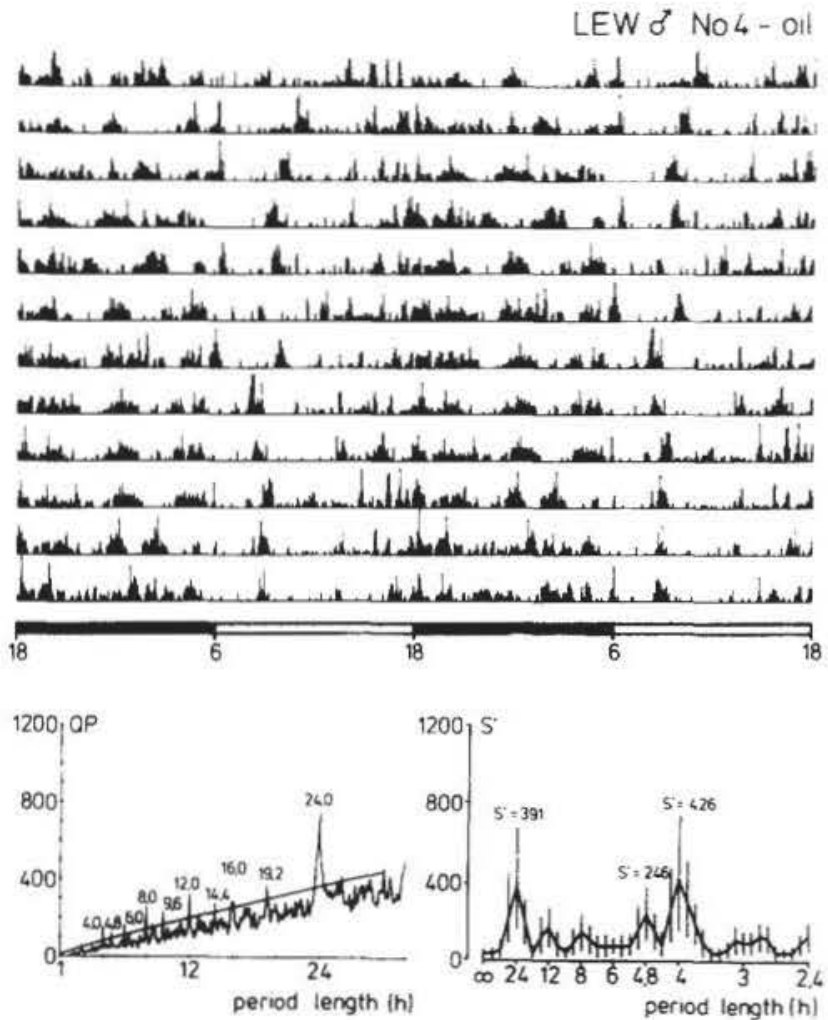

FIG. 5. Double plotted locomotor activity of a LEW male (No. 1) treated perinatally with cyproterone acetate and a control LEW male (No. 4) treated with oil alone. Both animals were measured for 13 days under LD 12:12. The chi square periodogram of these individual data is shown below the activity record of each animal on the left; the spectral analysis on the right.

TABLE 1

SIGNIFICANT RHYTHMIC COMPONENTS OF LESS THAN 24 HR PERIOD DETECTED BY THE SPECTRAL ANALYSIS AND THE CHI SQUARE PERIODOGRAM IN THE LOCOMOTOR ACTIVITY DATA OF 7 LEW/ZIm MALES DURING EXPERIMENT 2

\begin{tabular}{|c|c|c|c|c|c|c|c|c|}
\hline Animal & Day 1-18 & Day & $30-41$ & \multicolumn{3}{|c|}{ Day 43-57 } & \multicolumn{2}{|c|}{ Day 64-81 } \\
\hline 1 & 4 & & $\begin{array}{ll}44.8 \\
4\end{array}$ & 2.6 & & 4.8 & & \\
\hline 2 & 44.8 & 3 & 4 & & 3 & & & \\
\hline 3 & 4 & & 4.8 & & & 4.8 & 2.5 & 3 \\
\hline 4 & 4 & 3 & 44.8 & 2.6 & 3 & 4.8 & & 3 \\
\hline 5 & 4 & 33.4 & 4 & & 3.4 & 4 & & \\
\hline 6 & 4 & & 4 & & & 4 & & \\
\hline 7 & 44.8 & & 4.8 & & & 4 & & \\
\hline
\end{tabular}

Rhythmic components of distinct time intervals were derived for each animal by using the spectral analysis $[26,38]$ and the chi square periodogram [49]. Statements about the period of significant ultradian components were based on the application of both methods. Significant peaks in the periodogram were determined according to a $p \leqslant 0.001$ level of significance. As shown previously, an ultradian rhythm with a period of 4 hours results not only in a peak at $4.0 \mathrm{hr}$, but also in peaks at $8.0,12.0,16.0 \mathrm{hr}$ ect. This, likewise, holds for other ultradian rhythms. As a result, a series of multiple ultradian peaks was always interpreted as being caused by only one rhythmic component; i.e. the component of the shortest period. The 24-hr rhythm, which was present in all analyses, was not included in this table. 4.8-hr spectral estimates decreased to initial levels. As shown on the right side of Fig. 2, similar results were obtained with the chi square periodogram analysis of these data. Significant ultradian periodicities were observed during the second phase of the experiment only.

The effects of ovariectomy and estradiol replacement were observed in each of the $5 \mathrm{LEW} / \mathrm{Ztm}$ females studied. These results are shown in the pooled spectral analyses of Fig. 3. The pooled spectrum of the first experimental phase showed a single clear $24-\mathrm{hr}$ component. After ovariectomy additional ultradian peaks of $4 \mathrm{hr}\left(\mathrm{S}^{\prime}=240 \pm 50\right)$ and $4.8 \mathrm{hr}$ $\left(\mathrm{S}^{\prime}=362 \pm 143\right)$ periods appeared in the spectrum. The amplitudes of these ultradian components were significantly higher $(p \leqslant 0.01)$ than the corresponding values both before ovariectomy and after E2-replacement.

These hormonal treatments did not appear to effect the 24-hr rhythm. Although the amplitude of the 24-hr spectral estimate seemed to be lower after ovariectomy $\left(S^{\prime}=\right.$ $308 \pm 78$ ), these changes in the amplitude are insignificant. Although inspection of the ovaries after ovariectomy detected the presence of corpora lutea, no alterations in the activity onset that might depend upon the stage of estrous cycle were detectable during the first 18 days.

In conclusion, it is obvious from experiment 1 that ovariectomy and E2-capsule implantation have dramatic effects on the activity pattern of female LEW/Ztm rats. Following ovariectomy the females exhibited ultradian rhythms similar to those shown by untreated males of this strain. It seems likely that physiological levels of estradiol normally prevent ultradian rhythms in adult females. 
EXPERIMENT 2: EFFECT OF CASTRATION AND ESTRADIOL IMPLANTATION ON THE ULTRADIAN ACTIVITY PATTERN OF ADULT LEW/Ztm MALES

\section{Method}

Locomotor activity was measured under LD 12:12 in 7 adult male rats of the LEW/Ztm strain starting at approximately 80 days of age. All animals were recorded under these conditions for a period of 20 days. On day 21 , five males (Nos. 1-5) were castrated (GOX) under anesthesia, two further males (Nos. 6 and 7) were sham operated. The animals were monitored for an extended period of 35 days to ensure elimination of testosterone from the plasma. Ultradian rhythms persisted throughout the whole testing period after castration. On day $56,15 \mathrm{~mm}$ estradiol capsules (E2-capsule) were implanted in the lower thoracic region of five animals (Nos. $1,2,5-7$ ). Two animals (Nos. 3 and 4) were sham operated. The measurements of locomotor activity continued until day 80 .

\section{Results}

Figure 4 shows the effect of castration (GOX) and estradiol implantation (E2-capsule) on the activity pattern of one representative LEW/Ztm male (No. 2). During the first 20 days under LD 12:12 this animal exhibited a clear 24-hr rhythm. The amplitudes of the spectral estimates ranged between $S^{\prime}=400$ and $S^{\prime}=700$. The continuous spectral analysis showed additional significant ultradian rhythms of $4.8 \mathrm{hr}, 4$ $\mathrm{hr}$, and $3.4 \mathrm{hr}$ periods. In the periodogram, ultradian rhythms of $4.8 \mathrm{hr}$ and $4 \mathrm{hr}$ periods were detected. The ultradian activity pattern was not abolished by castration of the animal on day 21 . The 24 hr component as well as the ultradian components persisted, but a 3 -hr component became more prominent.

Implantation of an E2-capsule on day 56 had a dramatic effect on the circadian rhythms. Within a few days after implantation the amplitudes of the determined ultradian spectral estimates decreased to a non-significant level.

As shown on the right in Fig. 4, these effects of castration and E2-implantation were confirmed by the chi square periodogram analysis of these data. The periodogram from days 1-18 showed significant ultradian rhythms of 4 and 4.8 $\mathrm{hr}$ periods. The analysis of days $43-56$ detected a main 3-hr rhythmic component. The periodogram from days $64-81 \mathrm{did}$ not indicate any such significant ultradian components.

These effects of castration and E2-implantation were generally observed in all of the similarly treated animals (Table 1). No differences appeared in the activity patterns of the castrated and sham operated animals. On the other hand, a clear difference between the animals with E2-implantation and those without was obvious. Two animals (Nos. 3 and 4) which were sham operated on day 56 failed to show any reduction of ultradian rhythmicity during the experiment, whereas the animals with E2-implantation displayed no ultradian rhythms at all.

Although no statistical methods are available to secure the differences in the periods presented in Table 1 , it can be concluded from experiment 2 that testosterone has no effect on the ultradian activity pattern of the LEW/Ztm males. The direct role of estradiol on the inhibition of ultradian rhythmicity in males of this strain, however, was confirmed.

EXPERIMENT 3: EFFECT OF PERINATAL TREATMENT WITH AN ANDROGEN ANTAGONIST ON THE ACTIVITY PATTERN OF MALE LEW/Ztm RATS

Androgens are known to effect several sexually differ-
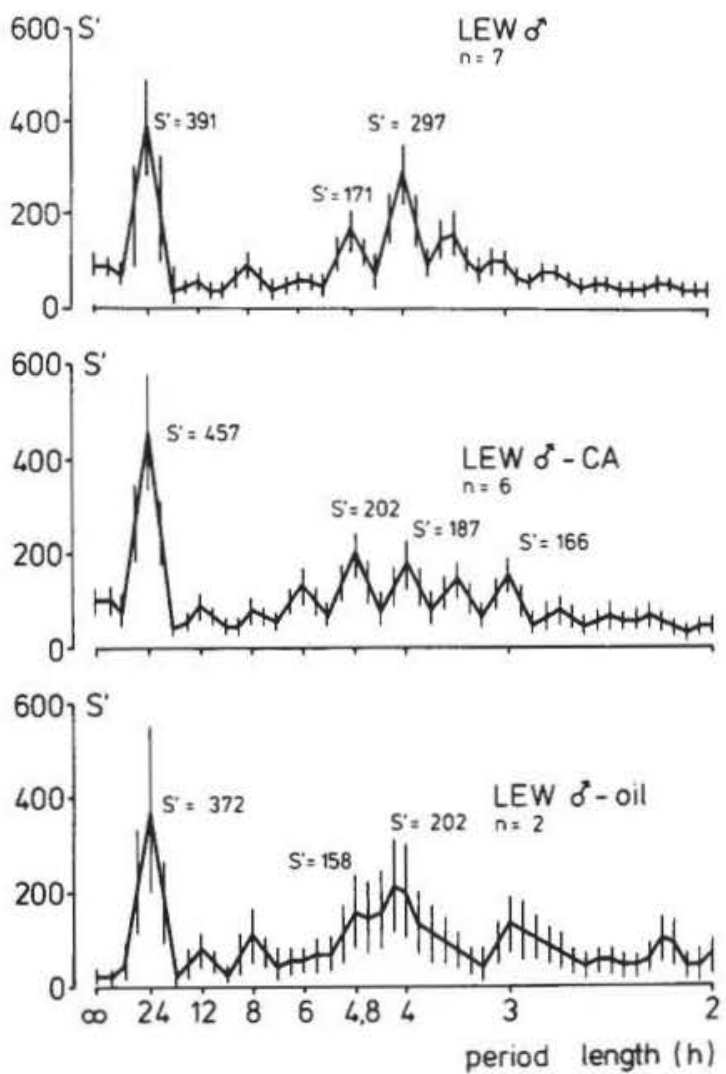

FIG. 6. Comparison of the pooled spectral analyses for normal LEW males (LEW $\delta ; n=7$ ) from experiment 2 with the cyproterone acetate-treated males (LEW $\delta-C A ; n=6$ ) and the oil-treated males (LEW $\delta$-oil; $n=2$ ) of experiment 3. All studies were done under LD 12:12.

entiated behaviors of the adult rat. In addition, these steroid hormones have a permanent masculinizing effect on the brain during a critical stage of development which in the rat is around the day of birth $[4,14,21]$. Experiment 3 was designed to examine the effect of an androgen antagonist, cyproterone acetate, in preventing perinatal androgenization $[4,20,37]$.

\section{Method}

Newborn LEW/Ztm pups of several litters were allocated to separate groups according to their sex and hormonal treatment. Afterwards, each group was treated separately and members of one group always received identical injections. These precautions excluded the possibility of potential contamination via hormone leakage from litter mates. Six males were given $0.5 \mathrm{mg}$ cyproterone acetate (Schering AG, Berlin) in $0.05 \mathrm{ml}$ corn oil for the first 10 days after birth ( $\delta$-CA). Two males received pure $0.05 \mathrm{ml}$ corn oil from day $1-10$ ( $\delta$-oil). The number of control animals was limited to two, because applicable data from 7 control males in experiment 2 were available for direct comparison. All animals were weaned at 28 days of age and were maintained under LD 12:12 in treatment-segregated groups. From approximately 80 days of age on, the animals were individually housed and locomotor activity was recorded for 13 days under LD 12:12. 

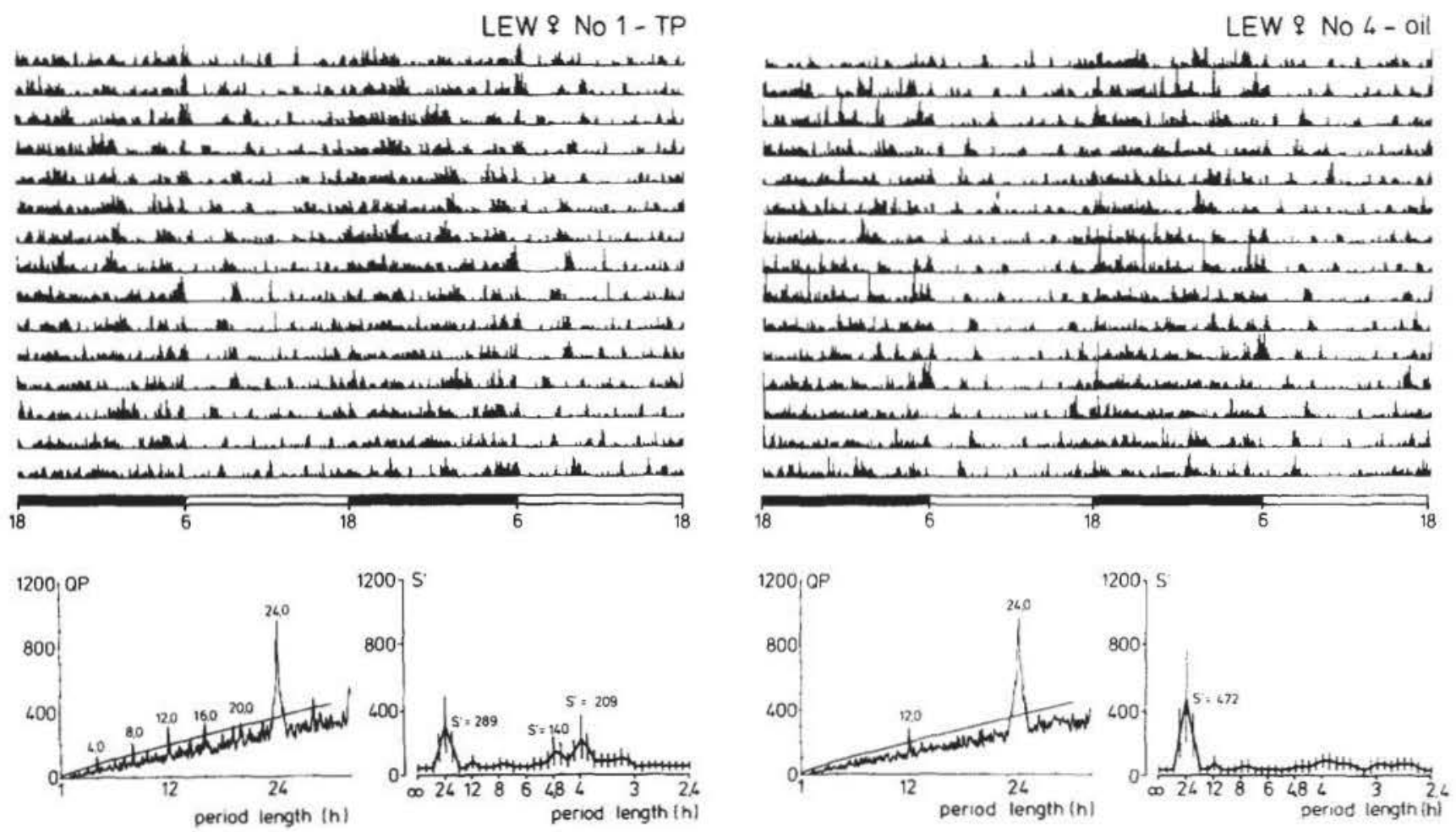

FIG. 7. Double plotted locomotor activity of two LEW females including a chi square periodogram and a spectral analysis of these individual data. Female No. I was perinatally treated with testosterone propionate. No. 4 was treated only with oil. Both animals were recorded under LD 12:12 for 16 days.

\section{Results}

Comparison of the activity patterns, the spectral analyses, and the chi square periodograms of two LEW/Ztm males is shown in Fig. 5. The LEW/Ztm male No. 4, treated with corn oil postnatally, showed a typical ultradian activity pattern of $4 \mathrm{hr}$ and $4.8 \mathrm{hr}$ period.

The activity pattern of the LEW/Ztm male No. 1, treated with cyproterone acetate postnatally, was also characterized by ultradian rhythms. Main rhythmic components of 4.8 and $3 \mathrm{hr}$ periods were evident.

The individual spectral analyses were pooled and are shown in Fig. 6. Statistical comparisons of the 4.8-hr and 4-hr spectral estimates as well as the 24 -hr spectral estimates indicated no significant differences in the amplitude of distinct spectral estimates between the untreated control males of experiment 2 (LEW $\delta$ ), the cyproterone acetate-treated males (LEW $\delta$-CA), and the oil-treated males (LEW $\delta$-oil). The amplitudes of the 4.8 and 4 -hr spectral estimates within both perinatally treated groups seemed to be somewhat lower than those found in the untreated LEW males. This effect may be due to considerable disturbances of the animals shortly after birth. Locomotor activity studies require conditions whereby the animals remain fully undisturbed. Therefore, treatment effectiveness on other behavioral endpoints was verified in separate groups of animals which received similar perinatal treatments (Döhler, unpublished results).

Perinatal treatment with cyproterone acetate was repeatedly shown to permanently feminize sexual behavior patterns and the mode of gonadotropic hormone release in males $[20,37]$. Such treatment, furthermore, inhibits the masculinizing effect of exogenous testosterone in females [4]. Cyproterone acetate does not, however, have any effect on the ultradian activity patterns in the LEW/Ztm strain.

EXPERIMENT 4: EFFECT OF PERINATAL TREATMENT WITH TESTOSTERONE PROPIONATE ON THE ACTIVITY PATTERN OF LEW/Ztm FEMALES

Current views of sexual differentiation suggest that perinatal exposure to androgens masculinizes the brain and results in a permanent loss of ovarian and vaginal cyclicity $[3,14,21]$. Preliminary reports indicate that androgens are also responsible for sexual differentiation of the circadian system of the rat and hamster $[1,13,58]$. Experiment 4 examines the effect of postnatal testosterone treatment on differentiation of the activity pattern of female rats.

\section{Method}

Newborn LEW/Ztm pups were weaned and maintained under the conditions described in experiment 3. An initial group of 6 female animals was injected with $50 \mu \mathrm{g}$ testosterone propionate (Serva Feinbiochemica, Heidelberg) in $0.05 \mathrm{ml}$ corn oil during the first 6 days after birth (LEW 9 TP). Two females received $0.05 \mathrm{ml}$ of pure corn oil (LEW 9 -oil). Measurements of locomotor activity started at approximately 80 days of age and continued for 18 days.

A second group of 6 females was injected with $50 \mu \mathrm{g}$ testosterone propionate in $0.05 \mathrm{ml}$ corn oil on days $1-6$. Activity recordings were performed with these animals for 18 days starting at approximately 80 days of age. On day 19 of 

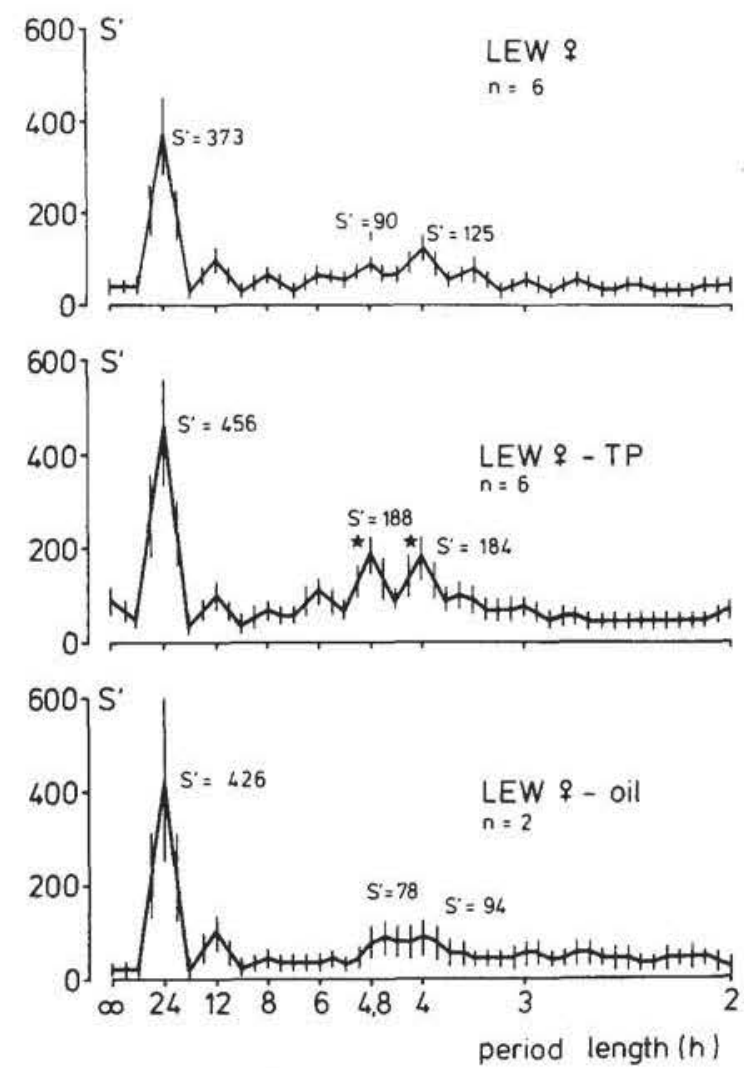

FIG. 8. Comparison of the pooled spectral analysis obtained for normal LEW females (LEW $;$, $=6$ ) from experiment 1 with the testosterone-treated females (LEW $\%$-TP; $n=6$ ) and the oil-treated females ( $L E W$ \% -oil; $n=2$ ) of experiment 4. The 4-hr and 4.8-hr spectral estimates of the LEW ?-TP are marked with stars, because they differ significantly $(p \leqslant 0.05)$ from the corresponding values of the normal and the oil-treated females.

measurement these animals were ovariectomized under anesthesia (LEW \&-TP + OVX) and were monitored for another 22 days. The effectiveness of the perinatal testosterone propionate treatment in this group was controlled by inspection of the ovaries. The ovaries were weighed and the presence or absence of corpora lutea was protocolled. Vaginal smears were not taken during the experiments, as handling would have disrupted the activity patterns.

\section{Results}

The activity patterns, the spectral analyses, and the chi square periodograms of two female rats are compared in Fig. 7. The control female rat No. 4 was perinatally treated with oil and showed the typical non-ultradian activity pattern of female LEW/Ztm rats. Female No. 1 which had been perinatally treated with testosterone propionate (TP) exhibited weak but significant ultradian rhythms of 4 and $4.8 \mathrm{hr}$ periods. The pooled spectral analyses obtained for the normal LEW/Ztm females of experiment 1, the testosterone propionate-treated animals (LEW 9 -TP), and the oil-treated animals (LEW $\%$-oil) are shown in Fig. 8. Statistical analysis of the data indicated no significant differences in the amplitudes of the 4-hr, 4.8-hr, and 24-hr spectral estimates between the untreated (LEW $\%$ ) and the oil-treated females
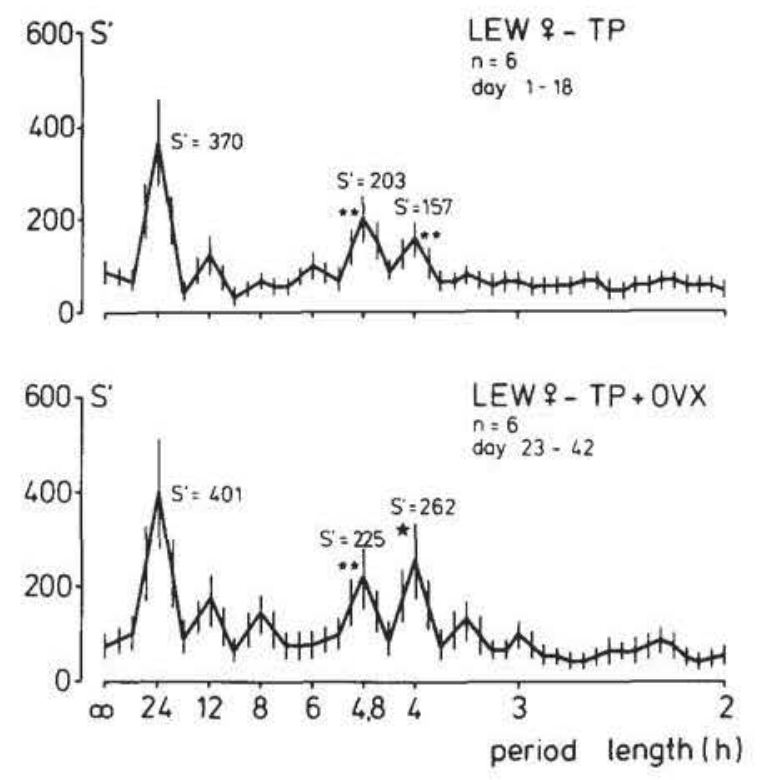

FIG. 9. Effect of ovariectomy on the activity pattern of perinatally androgenized rats. Pooled spectral analysis for testosterone-treated females during days 1-18 of the experiment (LEW $\%$-TP) and after ovariectomy (LEW $9-\mathrm{TP}+$ OVX, days 23-42). The 4-hr spectral estimate of the ovariectomized LEW -TP is marked with a star indicating that its amplitude is significantly higher $(p \leqslant 0.05)$ than the corresponding value of the non-ovariectomized LEW ?-TP. The 4.8-hr spectral estimate of the LEW?-TP-OVX, and the 4-hr and 4.8-hr spectral estimates of the LEW \%-TP females are marked with two smaller stars indicating that their amplitudes differ significantly $(p \leqslant 0.01)$ from the corresponding values of the untreated females (LEW?, Fig. 8) as well as those of the oil-treated females (LEW -oil, Fig. 8).

(LEW f-oil). Perinatal treatment with testosterone propionate (LEW 9 -TP) resulted in a significant increase $(p \leqslant 0.05)$ of the 4.8 -hr $\left(\mathrm{S}^{\prime}=184 \pm 91\right)$ and $4-\mathrm{hr}\left(\mathrm{S}^{\prime}=188 \pm 157\right)$ spectral estimates with respect to both the untreated (LEW $\%$ ) and the oil-treated control females (LEW $q$-oil).

The relative ovarian weights of the testosterone propionate-treated females were significantly lower than those of untreated females and none of them demonstrated corpora lutea. This observation confirmed the existence of permanent anovulatory sterility due to defeminization of the gonadotropin release pattern.

Female rats are normally characterized by cyclic hypophyseal gonadotropin secretion during sexual maturity. This can be indirectly demonstrated by the presence of corpora lutea in the ovaries. Perinatal treatment with testosterone propionate results in tonic gonadotropin release, leading to permanent sterility of the females ([14] for review) and in lower production of estradiol [3].

The persistence of the ultradian activity patterns in the testosterone-treated females may either be the result of a masculinized brain or the result of low estrogen levels in adulthood. This hypothesis was verified by a further experiment in which female rats were not only perinatally androgenized with testosterone propionate but were also ovariectomized as adults. The results of this treatment are 
shown in Fig. 9. During the first 18 days of measurement, the females showed increased amplitudes for the 4.8-hr $\left(S^{\prime}=203 \pm 32\right)$ and $4-h r\left(S^{\prime}=157 \pm 34\right)$ spectral estimates which did not differ significantly from those of the LEW $q-T P$ females in Fig. 8.

Ovariectomy resulted in a further increase of the ultradian spectral estimates, whereby alteration of the 4-hr spectral estimate $\left(S^{\prime}=262 \pm 76\right)$ was statistically significant $(p \leqslant 0.05)$. This supports the suggestion that expression and non-expression of ultradian activity patterns in this strain is directly related to the circulating levels of estradiol rather than to an organizational effect of testosterone.

\section{GENERAL DISCUSSION}

Gonadal hormones have two distinct effects on the circadian system. The presence of androgens during the perinatal period has a permanent organizational effect on the circadian system of hamsters $[13,33,57,58]$ and rats $[1,22]$, as on several other physiological and behavioral variables $[3,14$, $18,20,21]$. The results of the present study provide no evidence for a perinatal determination of the ultradian activity pattern by testosterone. Perinatal treatment of male $\mathrm{LEW} / \mathrm{Ztm}$ rats with cyproterone acetate, an androgen antagonist $[4,20,37]$, did not eliminate the ultradian activity pattern of the adult animals (experiment 3). Stimulation of the ultradian activity patterns in female rats when perinatally exposed to testosterone propionate (experiment 4) apparently contradicts the cyproterone acetate experiments. These contradicting observations can be explained by the fact that female rats perinatally treated with testosterone propionate display lower production levels of estradiol.

This leads to a second and more transient type of hormonal effect of circulating gonadal hormones in the adult animal. In male rodents, testosterone is known to increase the amplitude and to shorten the period of circadian activity rhythms [12]. Castration of adult LEW/Ztm males did not prevent ultradian rhythmicity (experiment 2 ) but seemed to effect the uniformity of the activity pattern. As shown in Table 1, non-castrated males (day $1-18$ ) normally exhibited one or two ultradian components of 4 and $4.8 \mathrm{hr}$ periods. Castration of these males (days 30-41 and 43-57) resulted in stimulation of rhythmic components with shorter periods (e.g., 2.6, 3, and 3.4 hr). Since these experiments were conducted under LD 12:12 entrainment, they do not allow for any clarification of the effect of testosterone on the endogenous ultradian rhythms.

Nevertheless, the results support previous observations which pointed out the correlation between the deterioration of precision in entrained hamsters and photoperiodic castration (i.e., testicular atrophy) during prolonged exposure to a short light-dark cycle [15]. Furthermore, exogenous testosterone was reported to restore running onset precision in hamsters [35]. Studies involving castration and testosterone replacement of male $\mathrm{LEW} / \mathrm{Ztm}$ rats under continuous light conditions, where the activity rhythms are not entrained to any lighting regime and therefore display their spontaneous periods, are needed to investigate the testosterone dependent changes in the activity pattern of this strain.

The results of this study demonstrate the effect of estradiol in the prevention of ultradian activity rhythms in laboratory rats of the LEW/Ztm strain. Estradiol released continuously from long-term subcutaneous implants generally prevented ultradian rhythms in ovariectomized females as well as in castrated and non-castrated males. As a result, this effect of estradiol can be added to the list of effects caused by this steroid on a biological rhythm system. The present results support the hypothesis that the ultradian activity pattern of this strain may be the result of a hormonally based change in the phase relationship between several circadian oscillators.

On the same line one would expect a $4-5$ day modulation in the activity pattern of sexually mature LEW-females, not only with respect to the onset and level of activity as previously found in rats $[2,19]$ and hamsters $[36]$, but also in the appearance of ultradian rhythms. Unfortunately, our data provide no such evidence of an estrous correlated modulation of the activity pattern. This is most likely caused by the capacitant system [44] used for measurement of locomotor activity, whereby all behavioral movements of the animal including feeding and grooming were registered.

In studies performed by Albers $e t a l$. [2] and by Gentry and Wade [18], no mention of ultradian rhythmicity was specifically made. Nevertheless, visual inspection of their running wheel data from female rats shows an obvious bi- or trimodal activity pattern on the days of di-, met-, and proestrous and an almost constant plateau of activity on the day of estrous.

Additional data have recently been presented which support the hypothesis that estradiol may uniformly strengthen the coupling between constituent oscillators. Circadian activity rhythms of hamsters exposed to constant illumination can be dissociated or split into components that free-run with different periods. Morin [34] has demonstrated that the administration of estradiol prevents splitting of the activity rhythm of ovariectomized female hamsters. Estradiol, likewise. inhibits other forms of abnormal rhythmicity classified by the presence of high or low frequency oscillations without obvious "splitting" [34].

In contrast to the hamster, where the circadian system is sexually differentiated and males do not apparently respond to exogenous estradiol [58], the present data did not show any sex-dependent effects of estradiol on ultradian rhythms in the LEW/Ztm rat. This is in agreement with data from a previous study [1] in which perinatal androgenization did not eliminate estrogen sensitivity in the circadian system of the rat. According to the structural model of the circadian pacemaker [40-43], "splitting" develops when mutual interactions between constituent oscillators cease as a result of a differential effect of light on the period of each oscillator. Daan $e t$ al. [12] proposed that hormones influence the length of circadian rhythms by strengthening or weakening the synchrony between the different oscillators which together govern circadian periodicity. Interpretation of the present data in the context of the coupling model presented above, suggests that estrogen suppresses the occurrence of circadian rhythms by uniformly strengthening synchrony between oscillators. Furthermore, the present data provide strong support for a multi-oscillator system with more than two oscillators regulating the activity rhythm in this special inbred strain of rats (i.e., three 24 -hr oscillations which are 4.8 hr out of phase). Hoffmann [27] has presented evidence for more than two free-running oscillators in the day-active animal Tupaia belangeri. The complex running patterns of arctic red-backed voles also suggest more than two oscillations regulating running rhythmicity $[50]$.

It is presently unknown what aspects of neural organization are responsible for the effect of estradiol on the internal clock. Various authors have pointed out that there are a variety of direct and indirect ways steroid hormones could 
influence the circadian system [12, 24, 25, 34-36, 51, 52, 57]. Evidence that the SCN does not accumulate high concentrations of radiolabeled estrogen in either rats or hamsters $[31,39]$ suggests that other areas of steroid uptake connected to the SCN (e.g., the preoptic-anterior hypothalamic area; $[10,55])$ may be involved in steroid effects on circadian rhythms. In addition, due to hormonal changes which are known to occur in response to alterations in circulating steroid levels, the effects of steroids on circadian rhythmicity may be mediated by other hormones (i.e., pituitary or hypothalamic hormones).

One of the most consistent effects of estrogens is the dramatic increase in various activities [10, 18, 19, 53-55]. In addition, steroid hormones also influence food intake [55], body weight [54] and a variety of autonomic functions in rodents [53]. Such observations support the alternative hypothesis that steroid hormones alter circadian properties by changing the general physiological state of an organism [51].

The described method of measuring locomotor activity [44] records overall integrated activity and does not differentiate between locomotion, feeding-related behavior and other types of activity.

Although the effect of estrogens on food intake is well known, it does not explain the observed effects of estrogens on ultradian activity. Estrogens stimulate food intake significantly more in control female rats than in males or androgenized females [18]. In our study, estrogens inhibited ultradian activity in both sexes equally. Our data correspond well with data on running wheel activity, where males and females responded equally to the effects of estrogen or progesterone $[1,19]$. Since the observed sex-differences in the activity pattern of the LEW/Ztm strain are not determined by perinatal androgenization, and since exogenous estrogen has the same effect in males and females, it is most likely that the observed sex-differences in the activity pattern of the LEW/Ztm strain reflect differences in locomotor behavior alone. Further investigations of this strain in the running wheel and measurements of feeding patterns and food intake are necessary to answer this question satisfactorily.

\section{ACKNOWLEDGEMENTS}

We wish to thank S. Lühmann for her help and technical assistance as well as K. Gärtner, T. R. Geimer, H. J. Hackbarth, A. Herrmann and $\mathbf{J}$. Kirchhoff for their comments on the manuscript. This research was supported by a grant from the Deutsche Forschungsgemeinschaft, SFB 146.

\section{REFERENCES}

1. Albers, H. E. Gonadal hormones organize and modulate the circadian system of the rat. Am J Physiol 241: R62-R66, 1981.

2. Albers, H. E., A. A. Gerall and J. F. Axelson. Effect of reproductive state on circadian periodicity in the rat. Physiol Behav 26: $21-25,1981$.

3. Arai, Y. Sexual differentiation and development of the hypothalamus and steroid-induced sterility. In: Neuroendocrine Control, edited by K. Yagi and S. Yoshido. New York: University of Tokyo Press, 1973, pp. 27-57.

4. Arai, Y. and R. A. Gorski. Critical exposure time for androgenization of the rat hypothalamus determined by antiandrogen injection. Proc Soc Exp Biol Med 127: 590-593, 1968.

5. Bingham, C., M. D. Godfrey and J. W. Tukey. Modern Techniques of Power Spectrum Estimation. Institute of Electrical and Electronics Engineers: Transactions on Audio- and Electroacoustics 1967, An 15: pp. 56-66.

6. Binkley, S. Computer methods of analysis for biorhythm data. In: Biological Rhythms in the Marine Environment, edited by P. J. DeCoursey. Columbia: University of South Carolina Press, 1976.

7. Binkley, S., K. Adler and P. H. Taylor. Two methods for using period length to study rhythmic phenomena. J Comp Physiol 83: 63-71, 1973.

8. Büttner, D. and F. Wollnik. Spontaneous short-term fluctuations in the daily pattern of heart rate, body temperature and locomotor activity in the laboratory rat. Lab Anim 16: 319 $326,1982$.

9. Büttner, D. and F. Wollnik. Strain-differentiated circadian and ultradian rhythms in locomotor activity of the laboratory rat. Behav Genet 14: 137-152, 1984

10. Colvin, G. B. and C. H. Sawyer. Induction of running activity by intracerebral implants of estrogen in ovariectomized rats. Neuroendocrinology 4: 309-320, 1969.

11. Daan, S. and J. Aschoff. Short-term rhythms in activity. In: Handbook of Behavioral Neurobiology, Vol 4, Biological Rhythms, edited by J. Aschoff. New York: Plenum Press, 1981, pp. 491-522.

12. Daan, S., D. Damassa, C. S. Pittendrigh and E. R. Smith. An effect of castration and testosterone replacement on a circadian pacemaker in mice (Mus musculus). Proc Natl Acad Sci USA 72: $3744-3747,1975$.
13. Davis, F. C., J. M. Darrow and M. Menaker. Sex differences in the circadian control of hamster wheel-running activity. Am J Physiol 244: R93-R105, 1983.

14. Dörner, G. Hormones and Brain Differentiation. Amsterdam: Elsevier Scientific Publishing Company, 1976.

15. Ellis, G. B. and F. W. Turek. Changes in locomotor activity associated with the photoperiodic response of the testes in male golden hamsters. J Comp Physiol 132: 277-284, 1979.

16. Enright, J. T. The search for rhythmicity in biological timeseries. $J$ Theor Biol 8: 426-468, 1965.

17. Festing, M. F.W. Inbred Strains in Biomedical Research. London: Macmillan, 1979.

18. Gentry, R. T. and G. N. Wade. Sex differences in sensitivity of food intake, body weight, and running-wheel activity to ovarian steroids in rats. J Comp Physiol Psychol 90: 747-754, 1976.

19. Gerall, A. A., A. M. Napoli and U. C. Cooper. Daily and hourly estrous running in intact spayed and estrone implanted rats. Physiol Behav 10: 225-229, 1973.

20. Gladue, B. A. and L. G. Clemens. Androgenic influences on feminine sexual behavior in male and female rats: defeminization blocked by prenatal antiandrogen treatment. Endocrinology 103: 1702-1709, 1978.

21. Gorski, R. A., R. E. Harlan and L. W. Christensen. Perinatal hormonal exposure and the development of neuroendocrine processes. J Toxicol Environ Health 3: 97-121, 1977.

22. Gorski, R. A. Evidence for a morphological sex difference within the medial preoptic area of the rat brain. Brain Res 148: 323-346, 1978.

23. GV-SOLAS. Liste der Erreger zur Spezifizierung bei SBFVersuchstieren Veröffentlichung der Gesellschaft für Versuchstierkunde Nr. 2, 1977.

24. Gwinner, E. Testosterone induces "splitting" of circadian locomotor activity rhythms in birds. Science 185: 72-74, 1974.

25. Gwinner, E. Effects of season and external testosterone on the free-running circadian activity rhythm of European starlings (Sturnus vulgaris). J Comp Physiol 103: 315-328, 1975.

26. Halberg, F. and H. Panofsky. I. Thermo-variance spectra; methods and clinical illustrations. Exp Med Surg 19: 285-321, 1961. 
27. Hoffmann. K. Splitting of the circadian rhythm as a function of light intensity. In: Biochronometry, edited by M. Menaker. Washington, DC: National Academy of Science. USA. 1971. pp. $134-146$

28. Honma, K. and T. Hiroshige. Simultaneous determination of circadian rhythms of locomotor activity and body temperature in the rat. Jpn J Physiol 28: 159-169. 1978.

29. Honma, K. and T. Hiroshige. Internal synchronization among several circadian rhythms in rats under constant light. $A m . J$ Physiol 235: R243-R249. 1978.

30. Honma, K. and T. Hiroshige. Endogenous ultradian rhythms in rats exposed to prolonged continuous light. Am J Physiol 235: R250-R256, 1978.

31. Krieger, M. S., J. 1. Morrell and D. W. Pfaff. Autoradiographic localization of estradiol-concentrating cells in the female hamster brain. Neuroendocrinology 22: 193-205, 1976.

32. Legan, S. J., G. A. Coon and F. J. Karsch. Role of estrogen as initiator of daily LH surges in the ovariectomized rat. Endocrinology 96: 50-56, 1975.

33. Mack, J. K.. W. T. Greenough and C. S. Carter. A Golgi study of the hamster suprachiasmatic nucleus. Soc Neurosci Abstr 7: $718,1981$.

34. Morin, L. P. Effect of ovarian hormones on synchrony of hamster circadian rhythms. Physiol Behav 24: 741-749, 1980.

35. Morin, L. P. and L. A. Cummings. Effect of surgical or photoperiodic castration, testosterone replacement or pinealectomy on male hamster running rhythmicity. Physiol Behaw 26: 825838. 1981.

36. Morin, L. P., K. M. Fitzgerald and I. Zucker. Estradiol shortens the period of hamster circadian rhythms. Science 196: 305-307, 1977.

37. Neumann, F. and W. Elger. Permanent changes in gonadal function and sexual behavior as a result of early feminization of male rats by treatment with an antiandrogenic steroid. Endohrinologie 50: 209-224, 1966.

38. Panofsky, H. and F. Halberg. II. Thermo-variance spectra; simplified computational example and other methodology. Exp Med Surg 19: 323-338, 1961.

39. Pfaff, D. and M. Kleiner. Atlas of estradiol-concentrating cells in the control of the nervous system of the female rat. I Comp Neurol 151: 121-158, 1973.

40. Pittendrigh, C. S. Circadian oscillation in cells and the circadian organization of multicellular systems. In: The Neurosciences, Third Study Program, edited by F. O. Schmitt and F. G. Worden. Cambridge, MA: MIT Press, 1974, pp. 437-458.

41. Pittendrigh, C. S. Circadian systems: General perspective. In: Handhook of Behavioral Neurobiology. Vol 4. Biological Rhythms, edited by J. Aschoff. New York: Plenum Press, 1981. pp. $57-81$.

42. Pittendrigh, C. S. Circadian systems: Entrainment. In: Handbook of Behavioral Neurobiology. Vol 4, Biological Rhythms. edited by J. Aschoff. New York: Plenum Press. 1981, pp. 95124.
43. Pittendrigh, C. S. and S. Daan. A functional analysis of circadian pacemakers in nocturnal rodents. V. Pacemaker structure: a clock for all seasons. $J$ Comp Physiol 106: 333-355, 1976.

44. Plonait. H., D. Büttner and U. Müschen. Ein kapazitiv arheitendes System zur Messung der Bewegungsaktivität kleiner Labortiere. Z Versuchstier 24: 244-249. 1982.

45. Rawson, K. S. and P. J. Decoursey. A comparison of the rhythms of mice and crabs from intertidal and interterrestrial habitats. In: Biological Rhythms in the Marine Environment. edited by P. J. DeCoursey. Columbia: University of South Carolina Press, 1976.

46. Rusak. B. Neural mechanisms for entrainment and generation of mammalian circadian rhythms. Fed Proc 38: 2589-2595, 1979.

47. Rusak. B. and I. Zucker. Neural regulation of circadian rhythms. Physiol Rev 59: 449-526, 1979.

48. Sokolove, P. G. and W. N. Bushell. The chi square periodogram: its utility for analysis of circadian rhythms. I Theor Biol 72: 131-160, 1978.

49. Stephan, F. K. Circadian rhythms in the rat: constant darkness, entrainment to T cycles and to skeleton photoperiods. Physiol Bcha1 30: 451-462, 1983.

50. Swade, R. H. A split activity rhythm under fluctuating light cycles. In: Biochronometry, edited by M. Menaker. Washington. DC: National Academy of Science USA, 1971, pp. 148-149.

51. Turek, F. W. and E. Gwinner. Role of hormones in the circadian organization of vertebrates. In: Vertebrate Circadian Systems: Structure and Physiology, edited by J. Aschoff, S. Daan and G. A. Groos. New York: Springer Verlag. 1982. pp. 173182.

52. Turek, F. W. J. P. McMillan and M. Menaker. Melatonin: effects on the circadian locomotor rhythms of sparrows. Science 194: $1441-1443,1976$

53. Wade, G. N. Gonadal hormones and behavioral regulation of body weight. Physiol Behav 8: 523-534, 1972.

54. Wade, G. N. Sex hormones, regulatory behaviors, and body weight. In: Adrances in the Study of Behavior, edited by J. S. Rosenblatt. New York: Academic Press, 1976, pp. 201-279.

55. Wade, G. N. and I. Zucker. Modulation of food intake and locomotor activity in female rats by diencephalic hormone implants. I Comp Physiol Psychol 72: 328-336. 1970.

56. Wollnik. F. Sex differences in the daily pattern of locomotor activity in laboratory rats. Naturwissenschaften 72: 158-161. 1985.

57. Zucker, I. Hormones and hamster circadian organization. In: Biological Rhythms and their Central Mechanism, edited by M. Suda, O. Hayaishi and H. Nakagawa. Elsevier: North-Holland Biomedical Press, 1979. pp. 369-381.

58. Zucker, I. K. M. Fitzgerald and L. P. Morin. Sex differentiation of the circadian system in the golden hamster. Am J Phvsiol 238: R97-R101. 1980. 